OPEN

SUBJECT AREAS:

MATERIALS CHEMISTRY

MATERIALS PHYSICS

MECHANICAL PROPERTIES

APPLIED PHYSICS

Received

13 March 2012

Accepted

11 May 2012

Published

23 May 2012

Correspondence and requests for materials should be addressed to

J.Q.W.

(junqiangwang@

wpi-aimr.tohoku.ac.jp)

\section{Excellent capability in degrading azo dyes by MgZn-based metallic glass powders}

\author{
Jun-Qiang Wang', Yan-Hui Liu', Ming-Wei Chen', Dmitri V. Louzguine-Luzgin', Akihisa Inoue ${ }^{2}$ \\ \& John H. Perepezko',
}

'WPI Advanced Institute of Materials Research, Tohoku University, Sendai 980-8577, Japan, ${ }^{2}$ Institute for Materials Research, Tohoku University, Sendai 980-8577, Japan, ${ }^{3}$ Department of Materials Science and Engineering, University of Wisconsin-Madison, 1509 University Avenue, Madison, WI 53706, USA.

The lack of new functional applications for metallic glasses hampers further development of these fascinating materials. In this letter, we report for the first time that the MgZn-based metallic glass powders have excellent functional ability in degrading azo dyes which are typical organic water pollutants. Their azo dye degradation efficiency is about 1000 times higher than that of commercial crystalline Fe powders, and 20 times higher than the $\mathrm{Mg}-\mathrm{Zn}$ alloy crystalline counterparts. The high $\mathrm{Zn}$ content in the amorphous Mg-based alloy enables a greater corrosion resistance in water and higher reaction efficiency with azo dye compared to crystalline Mg. Even under complex environmental conditions, the MgZn-based metallic glass powders retain high reaction efficiency. Our work opens up a new opportunity for functional applications of metallic glasses.

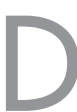

ecoloring (decomposing the $-\mathrm{N}=\mathrm{N}$ - bond in azo dyes) is, in general, an undesirable phenomenon for decorating and furnishing. However, in order to remediate water with contaminants that contain various azo dyes, achieving high efficiency in decolorization is of considerable interest. Among the various methods of degrading the organic water contaminants, reduction by zero-valent (zero oxidation state) metals has been documented as a highly efficient and low cost process ${ }^{1-4}$. In contrast, bacterial degradation methods have limitation in degrading some toxic azo dyes especially in a complex environment containing various chemicals ${ }^{5,6}$ while a carbon sorbent absorption method only collects the contaminants via a physical process but cannot degrade them ${ }^{7}$. The zero-valent $\mathrm{Mg}(\mathrm{ZVM})$ is of special interest due to its high efficiency in degrading various organic water contaminants ${ }^{5}$. Corrosion of pure $\mathrm{Mg}$ in water, however, reduces its endurance since a large amount of $\mathrm{Mg}$ can be consumed by water. Moreover, the decoration by $\mathrm{Pd}$ and $\mathrm{Pd}$ compounds has also been applied to enhance the Mg performance ${ }^{5}$, but this approach is costly. Therefore, it is of high interest to suppress the water corrosion process of $\mathrm{Mg}$ at low cost while simultaneously increasing the reaction efficiency with the dye.

The solid solution alloying is an effective way of improving the corrosion behavior of crystalline Mg alloys, but, in many cases, this method is highly limited by the low solubility of the desired alloying elements ${ }^{8-11}$. The glassy alloys, which have a unique atomic structure and special physical and chemical properties ${ }^{12-16}$, are promising candidates for this purpose because they offer an enhanced solubility of the alloying elements thus improving the corrosion resistance. Furthermore, the amorphous phase itself has excellent ionic corrosion resistance owing to the homogeneous microstructure and absence of grain boundaries and other defects ${ }^{17-19}$.

On the other hand, metallic glasses are metastable, and the constituent atoms do not reside at the thermodynamic equilibrium positions (corresponding to crystalline state) but locate in far-from-equilibrium states ${ }^{13,14,17}$. The metastable nature imparts many excellent properties to amorphous alloys that are unachievable for crystalline alloys, such as the good catalytic and chemical properties ${ }^{15,16,20-24}$. These properties can be widely tuned and optimized by controlling chemical composition, especially when the glass forming ability is not the major concern. In addition, the intrinsic brittleness of Mg- and Fe-based metallic glasses facilitates their communition into fine powders thus increasing their surface to volume ratio. The combination of their metastable nature, widely tunable compositions, and intrinsic brittleness makes the metallic glasses very attractive materials for degrading the water contaminants. 
Here we report that the ball-milled glassy Mg-based (BM G-Mg) alloy powders have excellent capability in degrading azo dyes in harsh environments at low temperatures. The glassy structure and high concentration of $\mathrm{Zn}$ are expected to improve the water corrosion resistance of the alloy and improve its reaction efficiency with azo dye.

\section{Results}

Characterization of BM G-MgZn powders. The structure of the powders is verified by XRD, as is shown in Fig. 1(a). The initial powders, the powders reacted with azo dye solutions, and the powders exposed in air for one week show an amorphous structure. The amorphous structure of the initial powders was further certified by high-resolution transmission electron microscopy (HRTEM) and nano-beam diffraction pattern, as is shown in Fig. 1(b). The morphology of the BM G-MgZn powders is shown in Fig. 1(c). It is evident that the particles are well dispersed without aggregation. The surface morphology of powder particles is characterized by high roughness and demonstrates the existence of corrugations. The particle size distribution shown in Fig. 1(d) provides an average diameter of $19.4 \mu \mathrm{m}$. Upon annealing at $300^{\circ} \mathrm{C}$ the powders crystallized to form $\mathrm{Mg}$ and $\mathrm{MgZn}$ intermetallics.

Azo dye degradation capability in aqueous solutions. The blue azo dye (Direct Blue 6, $\mathrm{C}_{32} \mathrm{H}_{20} \mathrm{~N}_{6} \mathrm{Na}_{4} \mathrm{O}_{14} \mathrm{~S}_{4}$ ) aqueous solution with concentration of $0.2 \mathrm{~g} / \mathrm{L}$ was used for evaluating the degradation ability. The azo bonding of Direct Blue 6 solution has a wide light absorption peak around $580 \mathrm{~nm}$ corresponding to the wavelength scale of green and yellow color, which can be seen in Fig. 2(a). Along with the degradation process, the azo bond $-\mathrm{N}=\mathrm{N}$ - breaks into
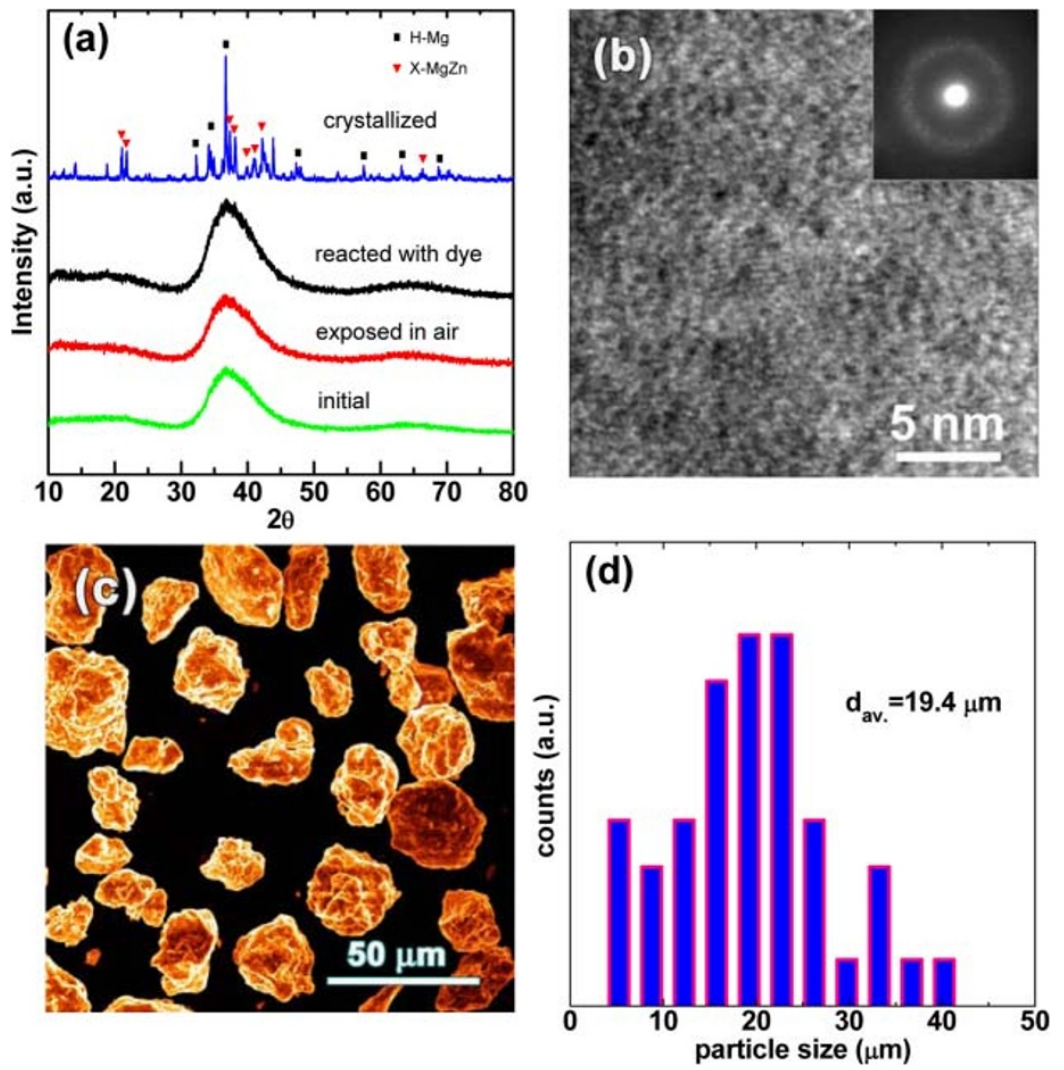
reaction endurance.

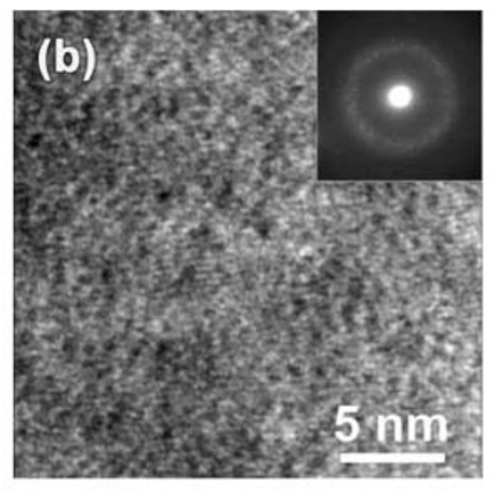

two $-\mathrm{NH}_{2}{ }^{25,26}$. The peak height in the absorption spectrum that is proportional to the concentration of azo dyes, will decrease and herein is used to characterize the Azo Dye concentration. The azo dye is degraded very fast in the first minute of exposure to BM G$\mathrm{MgZn}$ powders. After 10 minutes of exposure, the color of the solution disappears denoting that the azo bonding is degraded completely. This degradation process takes place much faster than that for the commercial Fe powders and the Fe-based metallic glass powders ${ }^{27}$, as can be seen in Fig. 2(b). The intensity decay behavior with time can be fitted by an exponential decay function according to the pseudo-first-order kinetic model ${ }^{5,28}, I=I_{0}+I_{1} e^{-\frac{t}{t_{0}}}$, where $I$ is the normalized intensity of the absorption peak, $I_{0}$ and $I_{1}$ are fitting constants, $t$ is the degradation time, and $t_{0}$ is the time when the intensity decreases to $e^{-1}$ of the initial state derived by fitting the experimental data. The reaction efficiency can be estimated by the value of $t_{0}$, as is shown in Fig. 2(c). The efficiency of G-MgZn powders $\left(t_{0}=0.78 \mathrm{~min}\right)$ is about 20 times faster than using the ball-milled Fe-based glass powders (BM G-Fe, $t_{0}=16 \mathrm{~min}$ ), and 1000 times faster than using the gas-atomization Fe-based glass powders (GA G-Fe, $t_{0}=810 \mathrm{~min}$ ) and commercial Fe powders (C$\mathrm{Fe}$ ), even though the Mg-based powders have a larger particle size and a reduced dosage is applied. After completion of the reaction, high-resolution SEM was used to examine the surface of the powder particles. The reaction products in form of nano-whiskers were observed to distribute uniformly and loosely on the surface of the G-MgZn particles, as is shown in Fig. 2(d). The uniform distribution without aggregation also denotes that the powder particles have high activity in this reaction. The loose structure of the reaction products on the surface cannot prevent further reaction and assures high

Figure $1 \mid$ (a) The XRD curves of the $\mathrm{Mg}_{73} \mathrm{Zn}_{21.5} \mathrm{Ca}_{5.5}$ powders. The initial BM G-MgZn powders, the powders reacted with azo dye solutions, and the powders exposed in air for one week show amorphous structure. The powders annealed at $300^{\circ} \mathrm{C}$ for 30 minutes show crystalline structures composed mainly of hexagonal Mg, MgZn phases and some complex intermetallics. (b) The HRTEM image illustrating formation of the amorphous structure. The inset shows the selected area nano-beam diffraction pattern. (c) The SEM image of the BM G-MgZn powders. (d) Distribution of the particle sizes with an average diameter of about $19.4 \mu \mathrm{m}$. 

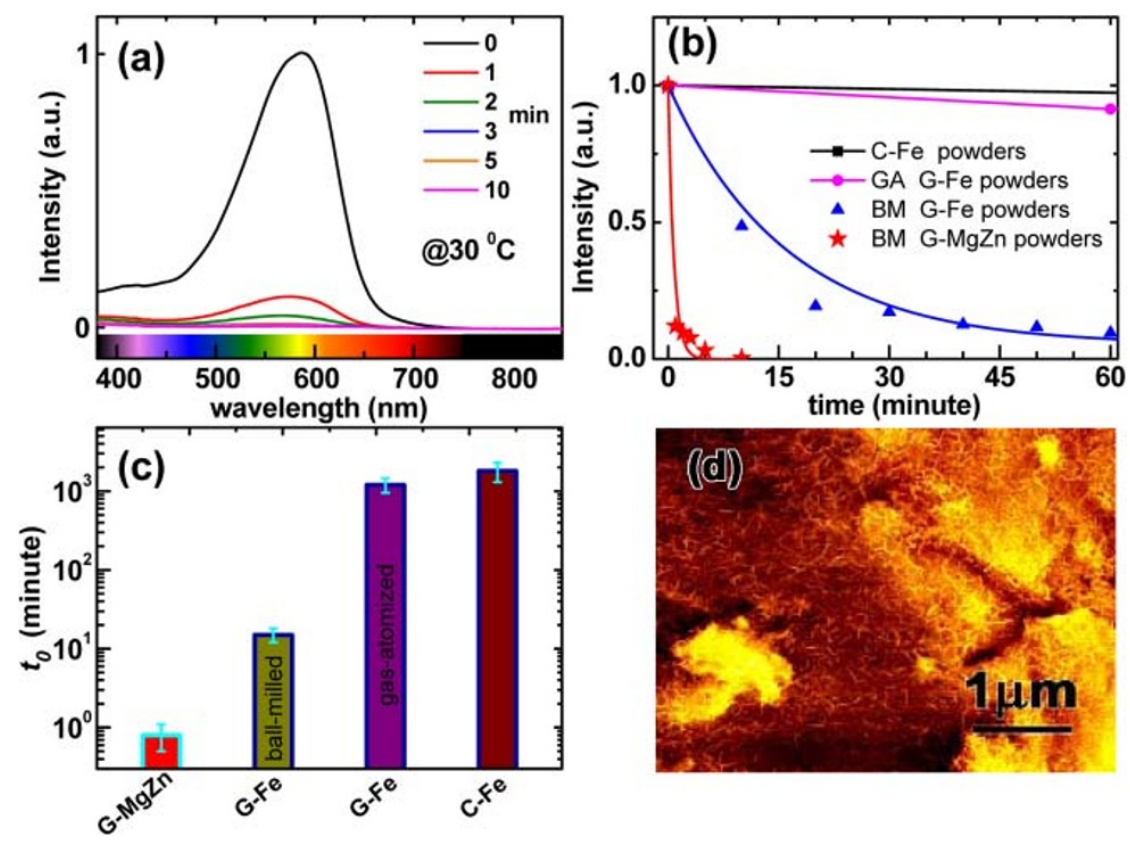

Figure $2 \mid$ (a) The UV absorption spectrum of the azo dye solutions decolored by G-MgZn powders for different time at $30^{\circ} \mathrm{C}$. The color spectrum bar is shown for guidance. (b) The degradation process by four different powder samples is indicated. (c) The comparison of the reaction efficiency of different metallic powders. (d) The high-resolution SEM image of the surface morphology of the reacted $\mathrm{Mg}_{73} \mathrm{Zn}_{21.5} \mathrm{Ca}_{5.5}$ glassy powder particle.

Reaction efficiencies in complex environments. The reaction efficiency was evaluated at different environment temperatures ranging from $45^{\circ} \mathrm{C}$ to $7^{\circ} \mathrm{C}$, as shown in Fig. 3(a). The reaction maintains a very high efficiency in the temperature range between 23 to $45^{\circ} \mathrm{C}$, with a slight slow down at $7^{\circ} \mathrm{C}$. The thermal activation energy barrier $\Delta E$ can be evaluated with the Arrhenius-type equation, $t_{0}=\tau_{0} \exp (\Delta E / R T)$, where $\tau_{0}$ is a time pre-factor, $R$ the gas constant. The $\Delta E$ is determined to be $51 \pm 23 \mathrm{~kJ} \mathrm{~mol}^{-1}$, where the large uncertainty is related to the very fast degradation speed for the initial one minute above $23^{\circ} \mathrm{C}$ so that resolving accurate $t_{0}$ values is difficult. Even with the uncertainty, the $\Delta E$ is smaller than that of the G-Fe powders, i.e. $78 \mathrm{~kJ} \mathrm{~mol}^{-1}$ for ball-milled G-Fe powders and $114 \mathrm{~kJ} \mathrm{~mol}^{-1}$ for gas-atomized G-Fe powders ${ }^{27}$ which indicates low temperature dependence for the degradation activity for G-Mg- $\mathrm{Zn}$ powders.

Slightly oxidized and the crystallized Mg-based powders were also examined. The degradation behavior of the absorption peak in comparison with the initial fresh powders can be found in Fig. 3(a). The degradation efficiency decreases after oxidation but the azo dyes can still be decomposed almost completely within 45 minutes, as shown
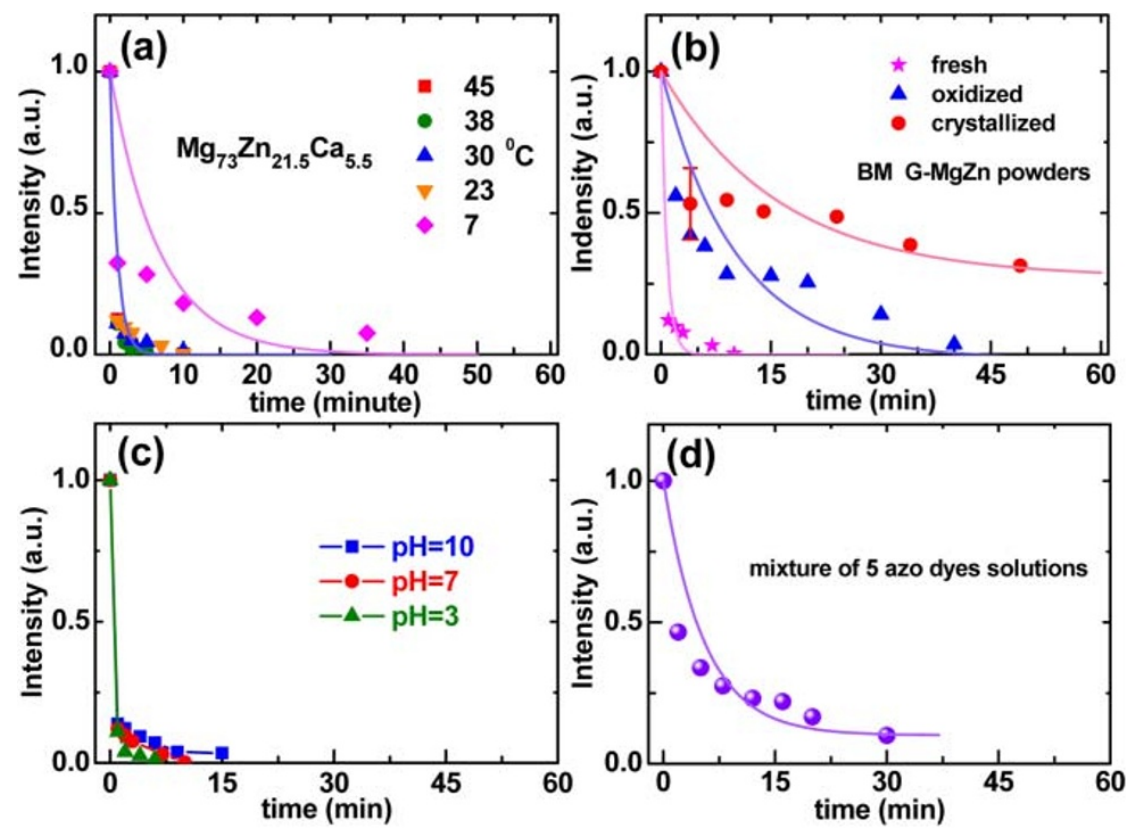

Figure $3 \mid$ (a) The normalized peak intensity at $580 \mathrm{~nm}$ as function of treatment time for the reactions at different temperatures. (b) The comparison of the reaction efficiency for the fresh BM G-MgZn powders (fresh, magenta stars), the powders exposed in air for 1 week (oxidized, blue triangles), and the powders annealed at $300^{\circ} \mathrm{C}$ for $30 \mathrm{~min}$ (crystallized, red circles). (c) shows the degradation efficiency at different $\mathrm{pH}$ values ( $\left.\mathrm{pH}=3,7,10\right)$. (d) shows the normalized peak intensity at $470 \mathrm{~nm}$ as a function of treatment time for the mixture solution of five different azo dyes. 
in Fig. 3(b). The crystallized powders, which contain mostly crystalline $\mathrm{Mg}$ phase and MgZn intermetallics, have a much lower degradation efficiency, especially during the late stage of reaction. The fitting results give $t_{0}=10.2 \mathrm{~min}$ and $16.1 \mathrm{~min}$ for oxidized and crystallized powders, respectively. These values are about 12 and 20 times lower than that of the fresh BM G-MgZn powder.

To examine the effect of $\mathrm{pH}$ level we prepared the solution with $\mathrm{pH}=3$ by adding $0.1 \mathrm{M} \mathrm{HCl}$ solution, and prepared the solution with $\mathrm{pH}=10$ by adding $0.1 \mathrm{M} \mathrm{NaOH}$ solution. For the initial one minute of the reaction, changing the acidity of the solution didn't change the reaction rate much, as is shown in Fig. 3(c). However, increasing the acidity can accelerate the degradation rate at the late stage. The azo dye can be degraded completely more quickly in solutions with low $\mathrm{pH}$ values.

The ability in degrading different azo dyes was also examined. Four other types of azo dyes with different characteristic absorption peaks were used for this evaluation, including Tartrazine $\left(\mathrm{C}_{16} \mathrm{H}_{9} \mathrm{~N}_{4} \mathrm{Na}_{3} \mathrm{O}_{9} \mathrm{~S}_{2}, 534.36 \mathrm{~g} / \mathrm{mol}\right)$, Methyl Orange $\left(\mathrm{C}_{14} \mathrm{H}_{14} \mathrm{~N}_{3} \mathrm{NaO}_{3} \mathrm{~S}\right.$, $327.34 \mathrm{~g} / \mathrm{mol})$, Sunset Yellow FCF $\left(\mathrm{C}_{16} \mathrm{H}_{10} \mathrm{~N}_{2} \mathrm{Na}_{2} \mathrm{O}_{7} \mathrm{~S}_{2}, 452.37 \mathrm{~g} / \mathrm{mol}\right)$, and Reactive Red $2\left(\mathrm{C}_{19} \mathrm{H}_{10} \mathrm{Cl}_{2} \mathrm{~N}_{6} \mathrm{Na}_{2} \mathrm{O}_{7} \mathrm{~S}_{2}, 615.33 \mathrm{~g} / \mathrm{mol}\right)$. The azo dyes were dissolved in deionized water with concentration of $0.1 \mathrm{~g} / \mathrm{L}$, separately. The UV absorption spectrum and the color image for each solution are shown in Fig. S1(a) and (b). The mixed solutions of the above 5 different azo dyes with the same amount and the same concentration $(0.1 \mathrm{~g} / \mathrm{L})$ were used to evaluate the reaction activity of BM G-MgZn powders. The UV absorption spectrum of the mixed solutions measured before reaction exactly corresponds to that obtained by a simple addition of the spectrums obtained for each solution independently, as shown in Fig. S1(c). This fact indicates absence of chemical reaction between the azo dyes.

The UV absorption spectrums obtained during the degradation process are listed in Fig. S1(d). The change of the peak intensity around $470 \mathrm{~nm}$ was used to evaluate the degradation efficiency, as shown in Fig. 3(d). It decreases quickly, with $t_{0}=5.5 \mathrm{~min}$, denoting a high reaction efficiency. Similarly, the reaction efficiency of the four azo dye solutions was studied separately, as shown in Fig. S2(a)-(h). The G-MgZn powders can degrade all of them in a short time. The Methyl Orange is the most difficult one to degrade with $t_{0}$ value of $9.39 \mathrm{~min}$, which is consistent with the degradation progress for the mixture of solutions. There is no clear relation between the degradation efficiency and the absorption peak wavelength, as shown in Fig. S2(i).

Corrosion resistance in water. Due to the low corrosion potential of $\mathrm{Mg}^{11}$, the fast corrosion by water can consume a significant amount of $\mathrm{Mg}$ and decrease its endurance, which is undesirable in the application of $\mathrm{Mg}$ in degrading the organic water contaminants. Thus, it is necessary to evaluate the water corrosion resistance of the present G-MgZn samples. The corrosion resistance of the G$\mathrm{MgZn}$ alloy was examined using the polarization corrosion method. The open circuit potential (OCP) of both $\mathrm{Mg}$ ribbon samples and G-MgZn ribbon samples in water and azo dye solution (direct blue $6,0.2 \mathrm{~g} / \mathrm{L}$ ) were measured, respectively, as is shown in Fig. 4(a). The OCP stabilized in $20 \mathrm{~min}$. While the OCP in azo dye solution is slightly lower than that in water for both of the materials, the G-MgZn ribbon has a much higher OCP than that of crystalline $\mathrm{Mg}$ ribbon, $-1.03 \pm 0.02 \mathrm{~V}$ for $\mathrm{G}-\mathrm{MgZn}$ ribbon and $-1.35 \pm 0.01 \mathrm{~V}$ for crystalline $\mathrm{Mg}$ ribbon. After the OCP stabilized, the potentiodynamic polarization behavior was measured for both materials in two liquids, which is shown in the form of $\log (i)$ versus the potential in Fig. 4(b), where $i$ is the corrosion current density. The anode corrosion current density of G-MgZn sample in water is several times lower than that of $\mathrm{Mg}$, which denotes that the GMgZn sample has a better corrosion resistance to water than that of crystalline Mg. The inset in Fig. 4(b) shows the linear relation between corrosion current density and polarization potential. The
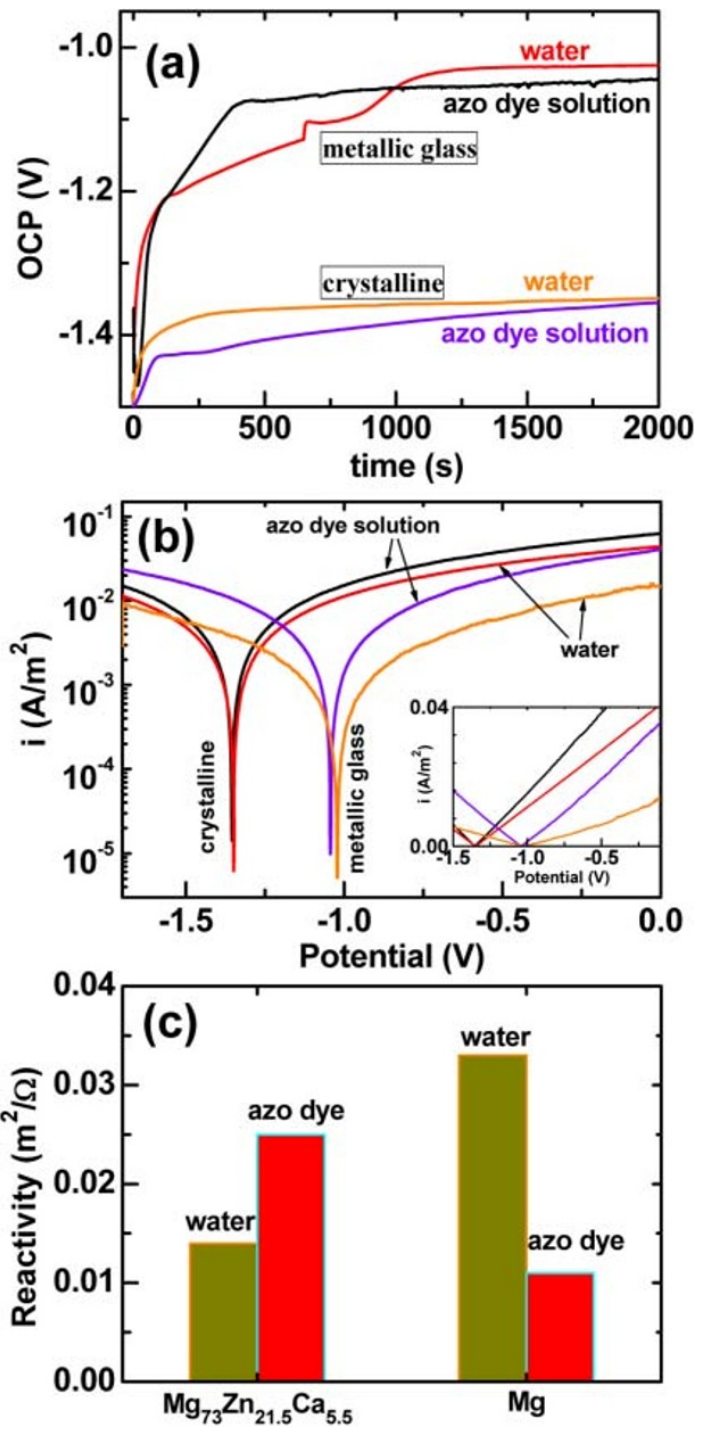

Figure $4 \mid$ (a) The OCP and (b) potentiodynamic polarization curves of glassy $\mathrm{Mg}_{73} \mathrm{Zn}_{21.5} \mathrm{Ca}_{5.5}$ and crystalline $\mathrm{Mg}$ ribbons in water and azo dye solutions, respectively. The inset shows corrosion current density $i$ and potential $V$ in linear coordinates. (c) The reactivity $(=\Delta i / \Delta V)$ of glassy $\mathrm{Mg}_{73} \mathrm{Zn}_{21.5} \mathrm{Ca}_{5.5}$ and crystalline $\mathrm{Mg}$ with water and azo dye.

slope of the plot yields the corrosion/reaction reactivity $\Delta i / \Delta V$ (reciprocal of corrosion resistance $\Delta V / \Delta i$ ). In water, the reactivity is determined to be 0.014 and $0.033 \mathrm{~m}^{2} / \Omega$ for G-MgZn sample and $\mathrm{Mg}$ sample, respectively. In azo dye solution, the reactivity is determined to be 0.039 and $0.044 \mathrm{~m}^{2} / \Omega$ for G-MgZn sample and $\mathrm{Mg}$ sample, respectively. It should be noted that the reactivity in azo dye solutions includes two independent parts: one is the reactivity with water and the other is reactivity with azo dye. Thus, the reactivity with azo dye can be obtained by subtracting the water reactivity from the solution reactivity. The reactivity of G-MgZn ribbon with azo dye is then determined to be $0.025 \mathrm{~m}^{2} / \Omega$, that is two times higher than that of $\mathrm{Mg}$ ribbon $0.011 \mathrm{~m}^{2} / \Omega$, as shown in Fig. 4(c). These results certify that the G-MgZn has higher reactivity with azo dye but lower reactivity with water than the crystalline $\mathrm{Mg}$.

\section{Discussion}

To distinguish the difference in the reaction kinetics of the G-MgZn and crystalline $\mathrm{Mg}$ samples, the change of component elements on the surface was measured using energy-dispersive X-ray (EDX) spectroscopy after 1 hour reaction with water and azo dye solutions 
(Fig. 5). The EDX spectroscopy results for the initial sample, the sample reacted with water and the sample reacted with azo dye solution are shown in Fig. 5 (a), (b) and (c), respectively. As the penetration depth of electrons in EDX is about $1 \mu \mathrm{m}$, it is sensitive in detecting the change of the component elements on the surface. The relative change in the composition of the component elements is shown in Fig. 5(d), which is normalized by the initial state (the numerical values can be found in the Table S1 in supplementary files). After reaction with water, the concentration of $\mathrm{Mg}$ decreases while the concentration of $\mathrm{Zn}$ and $\mathrm{Ca}$ increases greatly. This is similar to the situation observed in biological environments ${ }^{8}$. In effect, the preferential dissolution of $\mathrm{Mg}$ provides a surface enrichment in $\mathrm{Zn}$ that also enables a self-passivation capability ${ }^{1,8}$. The increased Ca concentration may arise from the deposition of the reacted $\mathrm{Ca}(\mathrm{OH})_{2}$. After the reaction with azo dye solutions, however, no obvious changes of the composition were detected. This denotes that the G-MgZn powders react uniformly with azo dye without compositional alteration.

The degradation process of azo dyes, in general, usually follows the pseudo-first-order kinetic model that is based on that the reaction rate is proportional to the concentration ${ }^{5,28}$. However, we find that the degradation behavior by the BM G-MgZn powders does not follow the exponential decay function well. The reaction is very fast in the initial one minute, but relatively slow in the subsequent stage. The ball-milling procedure produces abundant nano-features on the surface of the powder particles, which gives a high effective surface area. The residual stress after ball milling further enhances the reactivity. These factors contribute to the ultra-fast reaction speed at the initial one-minute of the reaction. The decrease concentration of azo dyes, disappearance of the surface nano-features of powder particles and the deposition of the reaction products along with reaction should be responsible for the subsequent slow of the reaction speed at the late stage. So, the reaction kinetics is complex and may change along with reaction process. The fitting by exponential function used here is to get a general reaction speed to be comparable with other works but not to explain the reaction mechanism. It is worthy to study reaction kinetics in details in future.

The ball-milling procedure may produce some wear debris and contamination stemming from milling tools, even though we milled the powders at low jar-rotating speed and for a short time. The XRD pattern certifies that the amount of contaminants is too low to be detectable. As we used steel jar and balls, the main element of the wear debris and contaminants should be Fe. The crystalline Fe is also active in degrading the azo dyes but has low reaction efficiency. Thus, it should not be responsible for the high reaction efficiency observed in this work.

In summary, the present results clearly demonstrate that $\mathrm{Mg}$ based glassy powders exhibit superior reaction efficiency in degrading azo dyes compared to Fe-based powders, their crystalline counterparts and crystalline $\mathrm{Mg}$. The high reaction efficiency can be retained in complex environments, such as solutions with different $\mathrm{pH}$ values and containing various azo dyes, at low temperatures. The combination of the metastable nature and the ball-milling induced high roughness on the surface bestows the metallic glass powders with high reaction capability in degrading the azo dyes. The glassy structure of the sample allows for a high solubility of $\mathrm{Zn}$, which improves the water corrosion resistance of the alloy and improves the reaction efficiency with azo dye. It is worthwhile to point out that the glassy MgZn-based powders are much more inert when exposed to the air, while the crystalline $\mathrm{Mg}$ powder easily undergoes autoignition which limits its applications. Generally, this functional application of $\mathrm{Mg}-\mathrm{Zn}$-Ca metallic glasses is not limited by their relatively low glass forming ability, and their intrinsic brittleness is a favorable feature. This may open a new broad field for functional applications of metallic glasses.
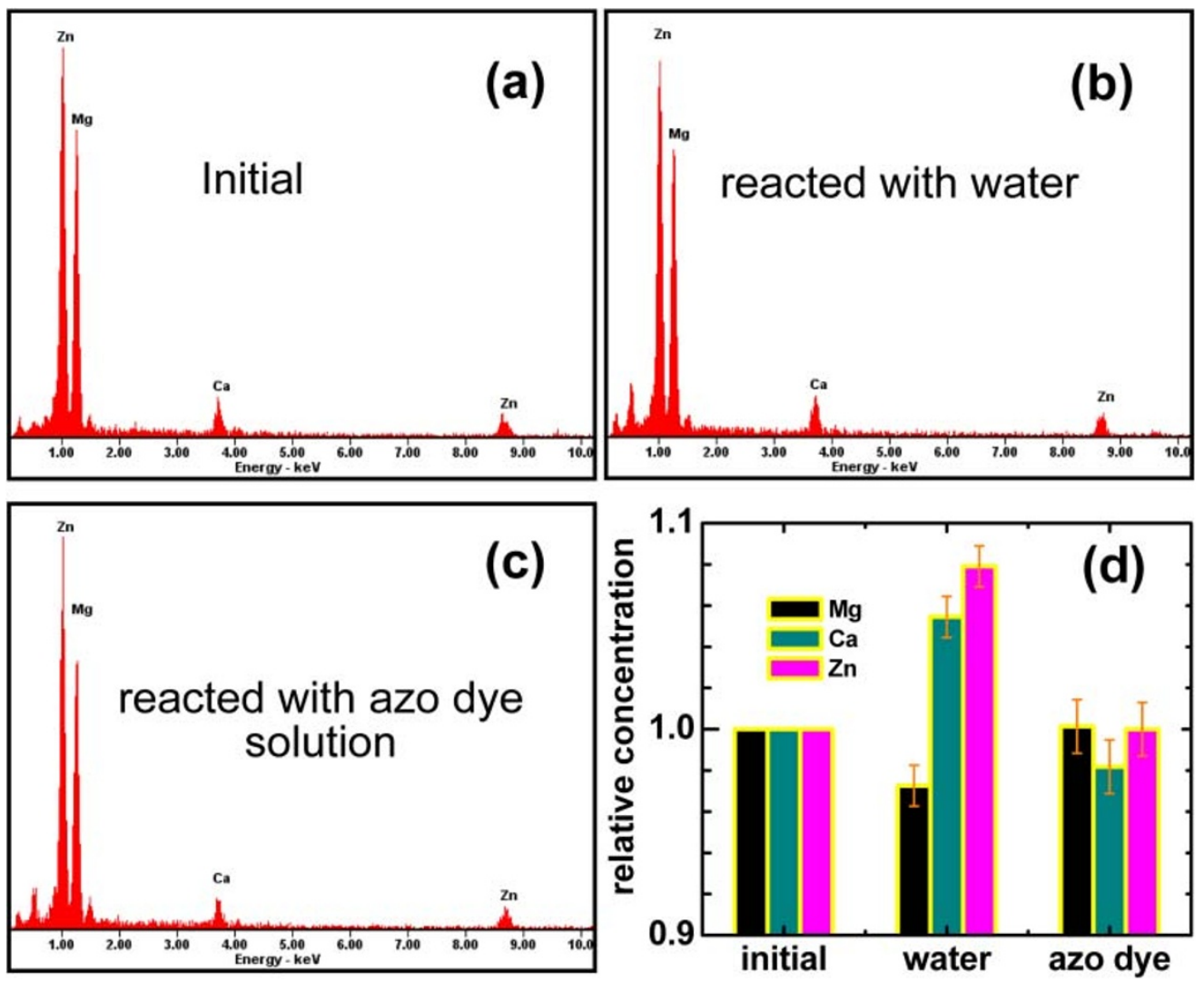

Figure $5 \mid$ The nominal compositions as examined by EDX: for initial sample (a), the sample reacted with water (b) and that with azo dye solution (c), respectively. (d) The relative concentration of the component elements detected by EDX. 


\section{Methods}

Fabrication of BM G-MgZn-based powders. Pure elements with high purity (>99.9 wt.\%) were designed with the nominal composition of $\mathrm{Mg}_{73} \mathrm{Zn}_{21.5} \mathrm{Ca}_{5.5}$ (at.\%) and melted in $\mathrm{BN}$ crucible using an induction-melting furnace. The master alloy was polished and then remelted in a quartz tube followed by subsequent injection casting onto a rotating $\mathrm{Cu}$ wheel to obtain metallic glass ribbon samples with a thickness of about $40 \mu \mathrm{m}$. The ribbon samples were then put into an evacuated ball-milling jar for communition into powders. For the above 3 steps, the sample chambers were firstly pumped to high vacuum $(<0.003 \mathrm{~Pa})$ and then backfilled with high purity Ar gas for protection. The rotating speed of the jar upon ball-milling was $250 \mathrm{r} / \mathrm{min}$. $1 \mathrm{~min}$ waiting interval was applied after each $5 \mathrm{~min}$ of milling to avoid the sample heating and then milled with inverse rotating direction. The total milling time was 2.5 hours. Some of the fresh powder samples were exposed in the air for one week to allow for oxidation. However, no detectable amounts of surface oxides can be observed using the XRD analysis. Some fresh powders were annealed under high vacuum $(<0.003 \mathrm{~Pa})$ at $300^{\circ} \mathrm{C}$ which is above the crystallization temperature determined by $\mathrm{DSC}^{9}$.

Reaction experiments. The azo dyes were purchased from Santa Cruz Biotechnology, Inc. The Direct Blue 6 azo dye solution was dissolved in deionized water forming a solution with concentration of $0.2 \mathrm{~g} / \mathrm{L}$ (the same as in previous works $\mathrm{s}^{23,27}$ to allow for comparison). The other four azo dyes solutions used in this work were $0.1 \mathrm{~g} / \mathrm{L}$. A decreased concentration was used to meet the maximum intensity of the UV measurement. Each time, $0.3 \mathrm{~g}$ of MgZn-base powders was added into $50 \mathrm{ml}$ azo dye solutions. After the reaction, about $1.5 \mathrm{ml}$ solution was taken out and filtered to measure the ultraviolet-visible (UV) absorption spectrum.

Characterization. The atomic structure of both the ribbon and the powder samples was studied by X-ray diffractometry (XRD) (Bruker D8 Advance, Cu K $\alpha$ X-ray) and high-resolution transmission electron microscopy (HRTEM) (JEOL 2010F). The powder morphology and size distribution was studied by SEM (Hitachi S-4800 Scanning Electron Microscope). The composition of the ribbon before and after reaction was determined by EDX equipped on the SEM machine. The UV absorption spectrum experiments were performed using Jasco V-650 Spectrophotometer. The OCP and polarization corrosion experiments were conducted using Hokuto Denko HZ-5000. The OCP was measured for more than $30 \mathrm{~min}$ to ensure its stabilization. The potential scanning rate used for polarization corrosion experiments was $2 \mathrm{mV} / \mathrm{s}$.

1. Salter-Blanc, A. J. \& Tratnyek, P. G. Effects of solution chemistry on the dechlorination of 1,2,3-Trichloropropane by zero-valent zinc. Environ. Sci. Technol. 45, 4073-4079 (2011).

2. Zhang, W. X. Nanoscale iron particles for environmental remediation: An overview. J. Nanoparticle Research 5, 323-332 (2003).

3. Arnold, W. A. \& Roberts, A. L. Pathways of chlorinated ethylene and chlorinated acetylene reaction with Zn(0). Environ. Sci. Technol. 32, 3017-3025 (1998).

4. Fennelly, J. P. \& Roberts, A. L. Reaction of 1,1,1-trichloroethane with zero-valent metals and bimetallic reductants. Environ. Sci. Technol. 32, 1980-1988 (1998).

5. Patel, R. \& Suresh, S. Decolourization of azo dyes using magnesium-palladium system. J. Hazard. Mater. 137, 1729-1741 (2006)

6. Kalme, S. D., Parshetti, G. K., Jadhav, S. U. \& Govindwar, S. P. Biodegradation of benzidine based dye Direct Blue- 6 by pseudomonas desmolyticum NCIM 2112. Bioresource Technology 98, 1405-1410 (2007).

7. Amin, N. K. Removal of direct blue-106 dye from aqueous solution using new activated carbons developed from pomegranate peel: Adsorption equilibrium and kinetics. J. Hazardous Materials 165, 52-62 (2009).

8. Zberg, B., Uggowitzer, P. J. \& Löffler, J. F. MgZnCa glasses without clinically observable hydrogen evolution for biodegradable implants. Nature Mater. 8, 887891 (2009).

9. Gu, X., Shiflet, G. J., Guo, F. Q. \& Poon, S. J. Mg-Ca-Zn bulk metallic glasses with high strength and significant ductility. J. Mater. Res. 20, 1935-1938 (2005).

10. Scully, J. R., Gebert, A. \& Payer, J. H. Corrosion and related mechanical properties of bulk metallic glasses. J. Mater. Res. 22, 302-313 (2007).
11. Song, G. L. \& Atrens, A. Corrosion mechanisms of magnesium alloys. Adv. Eng Mater. 5, 837-858 (2003).

12. Kumar, G., Tang, H. X. \& Schroers, J. Nanomoulding with amorphous metals. Nature 457, 868-872 (2009).

13. Greer, A. L. Metallic glasses. Science 267, 1947-1953 (1995).

14. Johnson, W. L. Bulk glass-forming metallic alloys: science and technology. MRS Bull. 24, 42-56 (1999).

15. Inoue, A. \& Takeuchi, A. Recently development and application products of bulk glassy alloys. Acta Mater. 59, 2243-2267 (2011).

16. Wang, W. H. Bulk metallic glasses with functional physical properties. Adv. Mater. 21, 4524-4544 (2009).

17. Inoue, A. Stabilization of metallic supercooled liquid and bulk amorphous alloys. Acta Mater. 48, 279-306 (2000).

18. Pang, S. J., Zhang, T., Asami, K. \& Inoue, A. Synthesis of Fe-Cr-Mo-C-B-P bulk metallic glasses with high corrosion resistance. Acta Mater. 50, 489-497 (2002).

19. Peter, W. H. et al. Localized corrosion behavior of a zirconium-based bulk metallic glass relative to its crystalline state. Intermetallics 10, 1157-1162 (2002).

20. Baiker, A. Metallic glasses in heterogeneous catalysis. Faraday Discuss. Chem. Soc. 87, 239-251 (1989).

21. Katona, T. \& Molnar, A. Amorphous alloy catalysis. J. Catal. 153, 333-343 (1995).

22. Carmo, M., Sekol, R. C., Ding, S., Kumar, G., Schroers, J. \& Taylor, A. D. Bulk metallic glass nanowire architecture for electrochemical applications. ACS NANO 5, 2979-2983 (2011).

23. Zhang, C. Q., Zhang, H. F., Lv, M. Q. \& Hu, Z. Q. Decolorization of azo dye solution by Fe-Mo-Si-B amorphous alloy. J. Non-Cryst. Solids 356, 1703-1706 (2010).

24. Lin, B., Bian, X., Wang, P. \& Luo, G. Application of Fe-based metallic glasses in wastewater treatment. Mater. Sci. Eng. B 177, 92-95 (2012).

25. Agrawal, A. \& Tratnyek, P. G. Reduction of nitro aromatic compounds by zerovalent iron metal. Environ. Sci. Technol. 30, 153-160 (1996).

26. Cao, J., Wei, L., Huang, Q., Wang, L. \& Han, S. Reducing degradation of azo dye by zero-valent iron in aqueous solution. Chemosphere 38, 565-571 (1999).

27. Wang, J. Q. et al. Rapid degradation of azo dye by Fe-based metallic glass powder. Adv. Funct. Mater. doi:10.1002/adfm.201103015.

28. Shu, H. Y., Chang, M. C., Yu, H. H. \& Chen, W. H. Reduction of an azo dye Acid Blue-24 solution using synthesized nanoscale zero-valent iron particles. J. Colloid Interface Sci. 314, 89-97 (2007)

\section{Acknowledgement}

The authors appreciate the help and discussions from Dr. T. Fujita, Dr. J.L. Kang and Dr. X.B. Ge. This work was supported by World Premier International Research Center Initiative (WPI), MEXT, Japan.

\section{Author contributions}

JQW, YHL, MWC and JHP designed the experiments. JQW carried out the experiments. DVL did the TEM experiment. All authors analyzed the data. All authors contributed in writing the paper.

\section{Additional information}

Supplementary information accompanies this paper at http://www.nature.com/ scientificreports

Competing financial interests: The authors declare no competing financial interests

License: This work is licensed under a Creative Commons

Attribution-NonCommercial-NoDerivative Works 3.0 Unported License. To view a copy of this license, visit http://creativecommons.org/licenses/by-nc-nd/3.0/

How to cite this article: Wang, J. et al. Excellent capability in degrading azo dyes by MgZn-based metallic glass powders. Sci. Rep. 2, 418; DOI:10.1038/srep00418 (2012) 